The vision in the right eye with the contact glass was 6/24 and on one occasion 6/18 partly and in the left eye nearly 6/60. He is able to read J.6 or a little more.

It seems that the use of contact glasses with liquid paraffin provides a valuable method of treating these otherwise hopeless cases and of improving their vision. The mucous membrane graft not only made the application of a contact glass to the left eye possible but also seemed to improve the general condition of the eye. I wish to express my indebtedness to Mr. Briggs for his original suggestion and to Mr. Phillips for his care and skill in carrying it out.

\title{
SOME CASES OF PARALYTIC SQUINT
}

BY

\section{P. G. DOYne \\ LONDON}

GeneRALISATIONS are attractive but perhaps at times dangerous. With regard to squint especially this may be so. With true concomitant squint I have always felt that the essential defect was in the central control and not primarily in any peripheral factor, although local conditions of the eyes themselves, as, for example, anisometropia, might decide which eye was used to fix with. That certain factors, in particular accommodative strain and psychological stress, caused the central control defect. That, in effect, concomitant squint was a posture conditioned by these factors.

Heterophoria, on the other hand, has seemed to me to be of an exactly opposite nature. That in this condition the defect was local and was for the most part held in check by the central control, only appearing as a naked eye defect when the central control was relaxed, or fatigued.

The following slogan seemed applicable: that in concomitant squint the more concentrated the gaze the more the squint; in heterophoria the more concentrated the gaze the less the squint.

There appears to me to be a certain resemblance between amblyopia and the fusion faculty. Amblyopia may be congenital or acquired; and the fusion faculty may be congenitally absent, or suppressed by disuse.

The fact that in so many cases of squint the fusion faculty will try to find an outlet by the development of "false correspondence," or by means of rapid alteration of the eyes, suggests a thwarted faculty rather than a defective one in the first place. 
With the more elaborate investigations of squint now made possible by the synoptophore, I have been surprised how often there appears to be some muscle weakness-an incomitance. In consequence, a follow-up of cases of congenital or early infantile paralytic squint with particular reference to the synoptophore findings I thought would prove of interest. I aimed to get cases from the age of about eight years and upwards, so that the paralysis would have been present for at least seven years. I found it most difficult to collect these cases. I suppose that after the presence of a paralysis has been established they have not been pressed to attend hospital further and in the course of years, having probably changed their address, they become untraceable. I have collected eight cases in all, though two of these are under the stipulated age.

1. Jean $H$., aged 10 years.-Paralysis of right external rectus since birth.

Vision: $R . \overline{\mathrm{c}} \frac{+2 \cdot 0 \text { D. sph. }}{+2 \cdot 0 \text { D. cyl. }} 6 / 12 . \quad$ L. $\overline{\mathrm{c}}+4 \cdot 0$ D. sph. $6 / 5$. Holds head slightly rotated to the right.

(a) With head rotated in this way eyes are parallel.

Synoptophore findings :

Simultaneous macular perception $\quad \ldots \quad$ at 0 .

$\begin{array}{lllllll}\text { Fusion } \quad \ldots & \ldots & \ldots & \ldots & \ldots & \text { at } 0 \text {. }\end{array}$

Some stereopsis $\ldots \quad \ldots \quad \ldots \quad \ldots \quad \ldots \quad$ at 0 .

(b) With head held straight R.E. converges $12^{\circ}$.

Synoptophore findings :

Simultaneous macular perception $\quad \ldots \quad 12^{\circ} \mathrm{C}$.

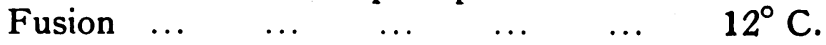

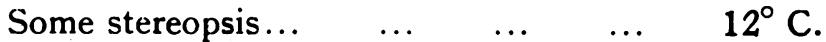

R.E. suppresses very readily and its vision has varied from $6 / 18$ to $6 / 9$.

2. Patricia B., aged 14 years.-Since early infancy paralysis right external rectus.

Vision: R. 6/6. L. $6 / 6$.

Diplopia on turning eyes to right.

Holds head rotated to right.

Synoptophore findings: with head rotated :-

Simultaneous macular perception $\quad \ldots \quad$ at 0 .

$\begin{array}{lllllll}\text { Fusion } & \ldots & \ldots & \ldots & \ldots & \ldots & \text { at } 0 \text {. }\end{array}$

$\begin{array}{llllll}\text { Some stereopsis } & \ldots & \ldots & \ldots & \ldots & \text { at } 0 \text {. }\end{array}$

3. Henry B., aged 11 years.-Right eye, defective lateral movement since birth.

On $R$. abduction, R.E. proptosis slightly.

On $L$. abduction, R.E. converges slightly and retracts slightly. 
Vision: $R . \overline{\mathrm{c}} \frac{+1 \cdot 0 \text { D. sph. }}{+0.5 \text { D. cyl. }} 6 / 6$. L. $\overline{\mathrm{c}}+2 \cdot 0$ D. sph. $6 / 6$.

Holds head slightly rotated to the right.

(With left eye fixing, right eye is convergent $6^{\circ}$ ) but in practice he rotates head to $R$. and by diverging L.E. obtains parallelism.

In this position:-

Synoptophore findings :

Simultaneous macular perception $\quad \ldots \quad$ at 0 .

Some fusion $\quad \ldots \quad \ldots \quad \ldots \quad \ldots \quad$ at 0 .

Easily relapses to false projection $\quad \ldots 3^{\circ}$ to $5^{\circ}$.

(b) With R.E. fixing, L.E. converges $31^{\circ}$.

Synoptophore findings :

True correspondence, objective and subjective angle, the same.

4. Ronald B., aged 10 years.-Left abduction defective but not quite absent-since birth.

Diplopia on looking to left.

Rotates head slightly to left.

Synoptophore findings :

When head rotated to left $\quad$... S.M.P. at 0.

When head not rotated $\quad \ldots \quad$ S.M.P. at $7^{\circ} \mathrm{C}$.

Suppresses very readily.

5. Jane M., aged 37 years.-Bilateral paralysis both external recti since ten months of age.

Vision: $R \cdot \overline{\mathrm{c}}+3 \cdot 0$ D. cyl. $6 / 9 . \frac{L .+1 \cdot 0 \text { D. sph. }}{+2 \cdot 5 \text { D. cyl. }} 6 / 9$.

Both eyes convergent $30^{\circ}$.

Head held with both eyes convergent.

On fixation (prefers L.E. but will fix with R.E.) rotates head in interest of fixing eye (e.g., to L. if L.E. is fixing).

In this case there is a complete harmonious false correspondence $\left(60^{\circ}\right.$ of false correspondence).

6 and 7. Angela K., aged 3 years. Helen M., aged $3 \frac{1}{2}$ years.Both cases have paralysis of the left external rectus.

Both hold their heads slightly rotated to the left and in this position the eyes appear parallel.

8. Grace $P$., aged 9 years.--R. ptosis and R. superior rectus paralysis since birth.

Vision: R. $\overline{\mathrm{c}}+2 \cdot 5$ D. sph. $6 / 5$. L. $\overline{\mathrm{c}}+2 \cdot 5$ D. sph. $6 / 5$.

With $L . E$. fixing. $R .-15^{\circ}$ divergence.

$10^{\circ} \mathrm{L} / \mathrm{R}$.

$3^{\circ}$ in-cyclophoria.

Marked suppression with either eye. 
No conclusions can be drawn from these few cases. There are points of interest. In the first four cases there is a marked similarity of practice. All four children rotate their heads in the interest of parallelism and in the rotated position have a fairly good, though not fully developed, fusion.

No false correspondence has developed except in one caseH. B., who tended to slip $3^{\circ}$.

The two little girls, cases 6 and 7, were too young for satisfactory synoptophore readings, but they appear to be developing along the same lines as the first four.

Case 5, with bilateral abduction paralysis, has developed a complete false correspondence and in this manner attempts to express her binocular sense.

Case 6, with the vertical paralysis, makes no attempt at binocular function, and does not posture.

My thanks are due to Miss Pugh, who very kindly worked out all the synoptophore findings.

\section{"BILATERAL MESIAL SUPERFICIAL DEFICIENCY OF THE SCLERA"}

BY

\section{Basil Graves}

IN "The Eye and its Diseases," edited by Dr. Conrad Berens (Messrs. Saunders \& Co., 1936), I briefly indicated in Fig. 184, H., p. 467 (and referred in the footnote at the bottom of page 468 ), to a condition which sometimes conveys, at the first casual glance, a suggestion of a tenotomy of the internal rectus having been performed in the past, due to a small sharply defined area where the sclera looks thinned, appearing usually less white than the surrounding scleral tissue. One or two colleagues have asked me for details of this condition. Magnified inspection reveals what is exemplified in Fig. 1 and Fig. 2 (which is Fig. 1 enlarged) and Fig. 3.

The optical appearance of these deficiencies is characteristic. If (Fig. 4) the focused small illuminating beam is directed through the over-lying conjunctiva into the middle of the depression (i.e., obliquely on to the floor, as in 1), the edge $\mathrm{AB}$, as seen through the over-lying conjunctiva, is displayed as a refractile sharply defined limit to what appears to be a superficial defect of the sclera (see Fig. 3, z, which is conjectural); the sides AC and $B D$ are less evident and the side $C D$ is only very faintly evident. 